\title{
O Emprego das Mídias Sociais no Policiamento: Um Estudo sob a Lente da Prática
}

Assumpção e Lima, Mirian; Alexandra Cunha, Maria

O Emprego das Mídias Sociais no Policiamento: Um Estudo sob a Lente da Prática

Administração Pública e Gestão Social, vol. 14, núm. 1, 2022

Universidade Federal de Viçosa, Brasil

Disponible en: https://www.redalyc. org/articulo. $0 a$ ? id=351569604001

\section{(c) (1) (9)}

Esta obra está bajo una Licencia Creative Commons Atribución-NoComercial-SinDerivar 4.0 Internacional. 


\title{
O Emprego das Mídias Sociais no Policiamento: Um Estudo sob a Lente da Prática
}

\author{
Social Media Employment in Policing: A Study from the Lens of Practice \\ El Empleo de Las Redes Sociales En la Vigilancia Policial: Un Estudio Desde La Práctica
}

Mirian Assumpção e Lima

Universidade Federal de Ouro Preto, Brasil

Redalyc: https://www.redalyc.org/articulo.oa?

mirianlimaop@gmail.com

Maria Alexandra Cunha

Fundação Getúlio Vargas, Brasil

alexandra.cunha@fgv.br

Recepción: 01 Diciembre 2020

Aprobación: 10 Julio 2021

Publicación: 08 Enero 2022

\section{Resumo:}

Objetivo da pesquisa: Explicar de que forma e com que finalidade as mídias sociais (MS) são empregadas no policiamento sob a lente da prática.

Enquadramento teórico: A Teoria da Estruturação e a Teoria Ator-Rede foram utilizadas como lentes teóricas para examinar processos e práticas organizacionais a partir de uma visão sociotécnica das redes de conexões empreendidas por atores humanos e não humanos.

Metodologia: Realizou-se um estudo de caso construtivista-instrumental com foco em uma questão específica relacionada ao fenômeno e não no caso em si. Os dados foram obtidos por meio de entrevistas, da observação participante e de documentos. $\mathrm{A}$ análise se deu a partir da narrativa e da codificação, com auxílio do software Atlas TI.

Resultados: As MS são empregadas no policiamento como fonte aberta de dados. Quanto à finalidade, são utilizadas na comunicação institucional para fortalecimento da imagem e na comunicação interna para agilizar os fluxos informativos. Também, para redução das lacunas de informação, possibilitando o acesso imediato aos dados. As MS funcionam como um amálgama, reduzindo distâncias geográficas, hierárquicas e contribuindo para o fortalecimento do espírito de corpo.

Originalidade: Antes de iniciar a pesquisa assumindo que as MS são empregadas para evoluir e melhorar a relação com o cidadão em uma determinada estratégia de policiamento, é necessário, primeiro, compreender como e para que as MS estão sendo utilizadas pelos policiais.

Contribuições teóricas e práticas: Apresenta-se um modelo do uso das MS no policiamento e a identificação da interatividade e da disponibilidade de dados como as características destacadas desse uso. Também, subsídios para uma melhor instrumentalização do uso das MS pelas polícias militares.

Palavras-chave: WhatsApp , Facebook, Polícia, Estudo de caso único, Método de Gioia.

\section{Abstract:}

Research objective: To explain how and for what purpose social media are used in policing under the lens of practice.

Theoretical framework: The Structural Theory and the Actor-Network Theory were used as theoretical lenses to examine organizational processes and practices from a socio-technical view of the networks of connections undertaken by human and nonhuman actors.

Methodology: An instrumental constructivist case study was carried out focusing on a specific issue in relation to the phenomenon rather than the case itself. The data were obtained through interviews, participant observation and documents. The analysis took place through narrative and coding with the aid of the Atlas TI software.

Results: SM are used in policing as an open source of data. As for the purpose, they are used in institutional communication, to strengthen the image and in internal communication to streamline information flows. Also, to reduce information gaps by allowing immediate access to data. SM work as an amalgam, reducing geographical and hierarchical distances, contributing to the strengthening of the body spirit.

Originality: Rather than starting the research assuming that MS are used to evolve and improve the relationship with the citizen in a given policing strategy, it is necessary to first understand how and for what SM are being used by police officers. 
Theoretical and practical contributions: A model of the use of SM in policing and the identification of interactivity and data availability are presented as the highlighted characteristics of this use. Also, subsidies for better instrumentalization of the use of SM by military police.

KEYWORDS: WhatsApp, Facebook, Police, Single case study, Gioia's method.

\section{RESUMEN:}

Objetivo de la investigación: Explicar cómo y con qué propósito se utilizan las redes sociales en la vigilancia policial desde la perspectiva de la práctica.

Marco teórico: La Teoría Estructural y la Teoría Actor-Red se utilizaron como lentes teóricos para examinar los procesos y prácticas organizacionales desde una visión socio-técnica de las redes de conexiones emprendidas por actores humanos y no humanos.

Metodología: Se realizó un estudio de caso constructivista instrumental que se centró en un tema específico en relación con el fenómeno y no con el caso en sí. Los datos se obtuvieron mediante entrevistas, observación participante y documentos. El análisis se llevó a cabo a través de la narrativa y la codificación con la ayuda del software Atlas TI.

Resultados: Los RS se utilizan en la vigilancia como una fuente abierta de datos. En cuanto al propósito, se utilizan en la comunicación institucional, para fortalecer la imagen y en la comunicación interna para agilizar los flujos de información. Además, para reducir las brechas de información al permitir el acceso inmediato a los datos. Los RS funcionan como una amalgama, reduciendo las distancias geográficas y jerárquicas, contribuyendo al fortalecimiento del espíritu corporal.

Originalidad: en lugar de comenzar la investigación asumiendo que los RS se utilizan para evolucionar y mejorar la relación con el ciudadano en una estrategia policial determinada, es necesario comprender primero cómo y para qué utilizan los agentes de policía. Contribuciones teóricas y prácticas: Un modelo del uso de la RS en la vigilancia policial y la identificación de la interactividad y la disponibilidad de datos se presentan como las características destacadas de este uso. Además, subvenciones para una mejor instrumentalización del uso de RS por parte de la policía militar.

Palabras Clave: WhatsApp, Facebook, Policía, Estudio de caso único, El método de Gioia.

\section{INTRODUÇÃO}

A polícia tem sido um campo de pesquisa para o qual têm se voltado as atenções da academia e das associações de chefes de polícia (IACP, 2011), buscando compreender como e para que as mídias sociais (MS) vêm sendo usadas, além de seus impactos na prática policial (Crump, 2011) e no relacionamento com a(o) cidadã(o) (Lieberman, Koetzle, \& Sakiyama, 2013; Davis, Alves, \& Sklansky, 2014; Grimmelikhuijsen, \& Meijer, 2015). Esses estudos foram realizados a partir do trabalho das polícias americanas e europeias, que possuem estruturas e atribuições muito diferentes daquelas da polícia brasileira, na qual o fenômeno ainda é pouco estudado (Porto, 2009).

Mesmo na literatura americana e europeia, são escassos os trabalhos que buscam discutir a contribuição das MS no contexto interno (intraorganizacional) da polícia (Meijer, 2014; Meijer, \& Torenvlied, 2016), pois o foco das pesquisas está, prioritariamente, na compreensão da influência das MS na relação com a(o) cidadã(o) (Lieberman, Koetzle, \& Sakiyama, 2013; Davis, Alves, \& Sklansky, 2014). Essa literatura sugere que a chave para a compreensão sobre os modos e as finalidades do emprego das MS é acessada essencialmente em nível organizacional. Talvez seja esse o motivo do reduzido número de estudos interpretativistas fundamentados na percepção do(a)s policiais de rua, embora diversas pesquisas sejam centradas na relação entre as MS e o policiamento comunitário (Crump, 2011; Brainard, \& Edlins, 2015), em que a participação desses policiais é fundamental.

Nesse sentido, uma análise sob a perspectiva da prática preenche uma lacuna tanto no campo das MS quanto no campo dos estudos sobre o trabalho policial. De fato, na maioria das pesquisas sobre tecnologia o foco está na causa ou efeito de seu uso, em razão do conjunto de propriedades materiais dessas ferramentas (Orlikowski, 2000). No caso do policiamento, a análise quase sempre se dá a partir de uma perspectiva positivista, como um processo individual, grupal ou organizacional, de maneira isolada e nem sempre situada (Manning, 2003). 
Esta pesquisa avança no campo, partindo do pressuposto de que a compreensão sobre o uso das MS pela polícia pode ser ampliada se for investigada a atividade construída por meio de ações e interações entre múltiplos atores e materiais envolvidos no trabalho policial. Assim, a lente da prática representa importante perspectiva analítica porque implica uma compreensão teoricamente fundamentada dessa interação recursiva dos atores entre si e com os materiais (Orlikowski, 2015). Nessa direção, a Teoria da Estruturação (TE) (Giddens, 2009) e a Teoria Ator-Rede (TAR) (Callon, 1986; Latour, 1999), aqui utilizadas como lente teórica, assentam-se em um paradigma interpretativista que permite examinar processos e práticas organizacionais a partir de uma visão sociotécnica das redes de conexões empreendidas por atores humanos e não humanos.

O principal argumento neste artigo é que há um ponto anterior na discussão sobre o emprego das MS pela polícia. Antes de iniciar a pesquisa assumindo que essas ferramentas são empregadas para evoluir e melhorar a relação com a(o) cidadã (o) em uma determinada estratégia de policiamento, é necessário, primeiro, compreender como e para que as MS estão sendo utilizadas pelo(a)s policiais. A partir de então é possível problematizar se, da maneira como esse uso tem se dado, há mudanças na prática policial e na relação da polícia com o cidadão. Esse argumento foi reforçado pela constatação de que os estudos nesse campo ainda são incipientes e pouco conclusivos para demonstrar a eficácia das MS no policiamento comunitário (Crump, 2011; Meijer, \& Thaens, 2013; Davis, Alves, \& Sklansky, 2014).

Por conseguinte, esta investigação buscou esclarecer como e para que as midias sociais são empregadas no policiamento. As MS analisadas foram o Facebook, o WhatsApp e os aplicativos Sinesp, Info Note, QApp e QAP Multas, desenvolvidos no Brasil especificamente para a segurança pública. Para isso, realizou-se um estudo de caso qualitativo construtivista (Langley \& Abdallah, 2011) e instrumental (Stake, 2005), em uma Polícia Militar (PM) brasileira.

Além da literatura sobre MS, polícia e policiamento, o quadro teórico de referência teve seus fundamentos fornecidos pelo esquema das dimensões da dualidade da estrutura, desenvolvido por Giddens (2009) em sua TE e incorporado por Orlikowski (2000) em seu modelo de tecnologia em prática; e pelo conceito de redes sociotécnicas, advindo da TAR (Latour, 1999). Os dados foram obtidos por meio de entrevistas, da observação participante e de documentos. A análise se deu a partir da narrativa (Langley, 1999; Fenton, \& Langley, 2008) e de codificação (Corley, \& Gioia, 2004; Strauss, \& Corbin, 2008), com auxílio do software Atlas TI.

$\mathrm{O}$ artigo está estruturado em sete seções, incluindo esta introdução que o apresenta. Na sequência, encontra-se o quadro teórico de referência com a articulação entre os domínios substantivo e teórico; a abordagem metodológica empregada para atingir o objetivo de pesquisa e, logo depois, a apresentação e análise dos dados. Após a discussão dos resultados encontrados, a última seção apresenta as considerações finais, as limitações do estudo e as propostas para novas pesquisas.

\section{O EMPREGO DAS MÍDIAS SOCIAIS NA POLÍCIA MILITAR}

Mídia social se tornou um termo amplamente utilizado e objeto de um crescente corpo de pesquisas acadêmicas, embora seja limitado o entendimento sobre sua definição (Ouirdi et al., 2014). Nesta pesquisa, orientada pelo paradigma interpretativista (Langley \& Abdallah, 2011) e por uma lente teórica da prática (Orlikowski, 2015), as MS são entendidas como aplicativos baseados na internet que permitem a interação social por meio da criação e troca de conteúdo entre usuários. Esse não é um conceito idiossincrático, pois foi elaborado a partir de Kaplan e Haenlein (2010), um dos trabalhos mais citados em pesquisas nesse campo (Ouirdi et al., 2014). Isso viabiliza comparações com outros estudos e vai permitir, no estudo empírico, a incorporação dos aplicativos desenvolvidos para segurança pública.

Com esse conceito, buscou-se também assegurar a importância da interação por meio de conteúdo compartilhado para compreender o emprego das tecnologias "não como incorporadas em determinados 
artefatos tecnológicos, mas como são adotadas pelas práticas sociais recorrentes de uma comunidade de usuários" (Orlikowski, 2000, p. 405). Igualmente, proporcionar a ideia de um movimento recursivo e articulado entre os atores humanos e não humanos, além da centralidade e relevância da troca de conteúdo para o policiamento. Na literatura sobre o tema, as características mais destacadas para o emprego das MS pelo setor público e, em especial, pela polícia, são a interatividade (Kaplan \& Haenlin, 2010; Crump, 2011; Davis, Alves, \& Sklansky, 2014; Brainard \& Edlins, 2015) e a disponibilidade de dados (Trottier, 2012, 2015).

O foco dos estudos sobre MS e polícia está, prioritariamente, na compreensão da influência dessas ferramentas tecnológicas na relação com o cidadão (Davis, Alves, \& Sklansky, 2014; Grimmelikhuijsen \& Meijer, 2015). Tais estudos partem do pressuposto de que as MS têm potencial para moldar o trabalho policial, contribuindo para a introdução de mudanças que possibilitam um aumento da eficiência. Para validação desse pressuposto, esses autores examinam as funcionalidades das MS, o perfil dos usuários e o conteúdo das mensagens (Lieberman, Koetzle, \& Sakiyama, 2013; O’Connor, 2015), além das estratégias para adoção e uso (Meijer \& Thaens, 2013; Trottier, 2015).

A polícia é definida na literatura como sendo uma força pública especializada e profissional (Bayley, 2001; Manning, 2005; Muniz e Proença, 2014). Por conseguinte, entender que a polícia é uma força pública autorizada a regular as relaçóes em uma sociedade, possibilita investigar o objeto deste estudo, uma vez que no Brasil há uma secção na atividade policial e as polícias militares são as principais responsáveis pelo emprego da força. Tal entendimento também oferece suporte para que se investigue como os policiais empregam as MS em sua atividade diária para regular as relações em uma sociedade.

O policiamento é formado por vários eventos, como patrulhamento, abordagem, assistência, busca, prisão, autuação, condução. Por vezes, são analisados isoladamente ou sequencialmente em um processo (de busca e apreensão, de abordagem e prisão) que agrega um extenso conjunto de ações (Bayley, 2001). Nesta pesquisa, considerou-se o policiamento como sendo açóes de patrulhamento e de resposta aos chamados dos cidadãos. Isso porque, tanto nas ações desenvolvidas ao patrulhar quanto na atuação policial, é possível observar as práticas locais e localizadas, nas quais o(a)s policiais empregam ferramentas e modelos mobilizados por meio do conhecimento tácito e coletivo.

Até alcançar o formato atual, as polícias militares no Brasil passaram por diversas alterações e inovações institucionais. O caráter militar da instituição - um exército estadual durante a Primeira República (1989-1930), com formação e ideologia de natureza bélica - teria sido apropriado e reelaborado nas décadas subsequentes: Força Pública, Força Policial, Polícia Militar. Em 1967, a Constituição e o Decreto-Lei 317 foram fundamentais para se entender a configuração atual dessas polícias, atribuindo-lhes a exclusividade no policiamento ostensivo fardado e abolindo a Guarda Civil uniformizada. A Constituição de 1988 não trouxe inovações em relação à definição do papel e à operacionalidade da polícia militar (Cotta, 2006; Oliveira, 2007).

A ideia de especialização na tarefa de enfrentar criminoso(a)s é o ponto inicial para entender como se dá o policiamento, mesmo sabendo que um volume significativo de chamadas se refere a atendimentos outros que não criminais. Esse caráter "militar", que acompanha a polícia ostensiva até hoje, levou ao entendimento do "combate ao crime" como sua missão institucional, sendo sua eficiência mensurada pela queda no número de ocorrências. A tecnologia, centrada no uso da viatura pelo(a)s policiais e na disponibilização de um número de emergência para a(o)s cidadã(o)s, reforça as ações policiais reativas em detrimento das proativas (Bayley, 2001; Manning, 2003; Oliveira, 2007). Para reverter esse quadro, a PM tem buscado soluções em novas tecnologias de informação e comunicação, como as mídias sociais.

À semelhança de outros órgãos governamentais, a polícia emprega as MS com a expectativa de ampliar a visibilidade de suas ações, pretendendo o aumento da eficácia e da legitimidade (Meijer \& Thaens, 2013). Além disso, espera mais participação e engajamento com o público, apostando no aumento da confiança e na decorrente redução do crime, embora enfrente resistências internas em razão dos riscos potenciais que a divulgação de informações sem uma censura prévia pode causar (Brainard \& Edlins, 2015). 


\section{A LENTE DA PRÁTICA}

Engajar-se com a prática na pesquisa implica em uma reconsideração explícita das premissas paradigmáticas, podendo a prática ser analisada como um fenômeno, como uma perspectiva ou como uma filosofia (Orlikowski, 2015). Nesta pesquisa, a prática foi adotada como uma perspectiva, articulando-se teorias e modelos sobre um fenômeno. As ações e os atores foram analisados como construídos por meio das práticas; o social, como sendo um campo de práticas incorporadas, organizado centralmente em torno de conhecimento prático compartilhado (Schakzti, 2005).

Um traço comum entre os constructos estabelecidos para prática reside na conexão entre ação individual e o que é normativo ou institucionalizado, superando a discussão entre agência e estrutura, na qual não o indivíduo, mas a relacionalidade, a ação e a interação, passam a ocupar o centro da análise social (Orlikowski, 2000, 2015). Para compreender e explicar o emprego das MS no policiamento, utilizou-se como arcabouço conceitual a Teoria da Estruturação (Giddens, 2009), o Modelo da Tecnologia em Prática (Orlikowski, 2000) e a Teoria Ator-Rede (Callon, 1986; Latour, 1999).

Para Giddens (2009), os agentes (ou atores humanos) representam as pessoas que operam no meio social e, por serem dotados de capacidade reflexiva, estão aptos a atuar e a compreender suas próprias ações. A agência representa a capacidade que as pessoas têm para fazer as coisas e não as intenções que teriam em praticar tais coisas. A estrutura é um elemento virtual criado pela prática, não existindo de forma independente da agência e não sendo, portanto, um elemento concreto e exógeno à ação humana.

$\mathrm{Na} \mathrm{TE}$, "a estruturação é colocada como um processo social que envolve a interação recíproca entre atores humanos e as características estruturais das organizações" (Orlikowski, 1992, p. 404). Assim, qualquer que seja o nível de coerção estrutural imposta à conduta de um agente, seu poder de agência lhe dá alguma possibilidade de "agir de modo diferente". Essa perspectiva de agência liberta os atores da concepção determinística da ação da estrutura sobre eles.

Giddens (2009) representa em três dimensões, de maneira esquemática, as interações entre a agência e a estrutura, denominadas pelo autor de dualidade da estrutura: (i) significado/comunicação; (ii) dominação/ poder; e (iii) legitimação/sanção. As modalidades da estruturação - esquemas interpretativos, recursos e normas - propiciam a interação mútua entre o domínio da ação humana e o domínio institucional. Assim, os esquemas interpretativos são veículos para a comunicação de significado. Os recursos são alocados por agentes humanos e se tornam a base para o poder individual e, uma vez legitimados, contribuem para estruturas de dominação. Já as normas, são regras e convenções que mantêm o comportamento dentro de limites aceitáveis e emergem de padrões de interação recorrentes entre agentes humanos baseados em noções pessoais do que é sancionado (Pozzebon \& Pinsonneault, 2000).

Fundamentada nas discussões de Giddens (2009) sobre a dualidade da estrutura, Orlikowski (1992) propôs o modelo "estruturacionista" da tecnologia, revisado posteriormente como o modelo da Tecnologia em Prática (Orlikowski, 2000), no qual o fenômeno da tecnologia é analisado pelas lentes da prática. A ideia foi reconstruir o conceito de tecnologia em sintonia com o seu uso e seu papel nas organizações, por ser essa uma variável central na teoria das organizações.

A lente da prática favorece a incorporação não apenas dos atores humanos, mas também, dos não bumanos, por meio da formação de redes sociotécnicas que articulam esses atores. Na TAR (Latour, 1999), os atores não humanos são vistos de maneira analiticamente simétrica aos humanos. O conceito de rede heterogênea dá clareza à ideia de que os atores tomam a sua forma e adquirem seus atributos como consequência das relações com os outros e implica em processos de transformação e de translação entre os atores. Ao transladar, os atores modificam e deslocam os seus vários e contraditórios interesses. A rede sociotécnica é considerada tanto o meio quanto o resultado das interações que, recursivamente e precariamente, gera e se reproduz em interações posteriores (Latour, 1999). 
As características e complementariedades dessas duas teorias permitiram explicar o emprego das MS no policiamento. $\mathrm{O}$ uso das MS na prática policial ocorre em uma rede sociotécnica constituída de atores humanos e não humanos. A TAR favorece a investigação dos processos que conduzem a construção e a transformação dessas redes, contribuindo para que sejam incluídos como partes essenciais da análise os recursos (Giddens, 2009) e suas relações, interfaces e ambientes físicos gerados nas redes. A representação esquemática desse quadro teórico é demonstrada na Figura 1.

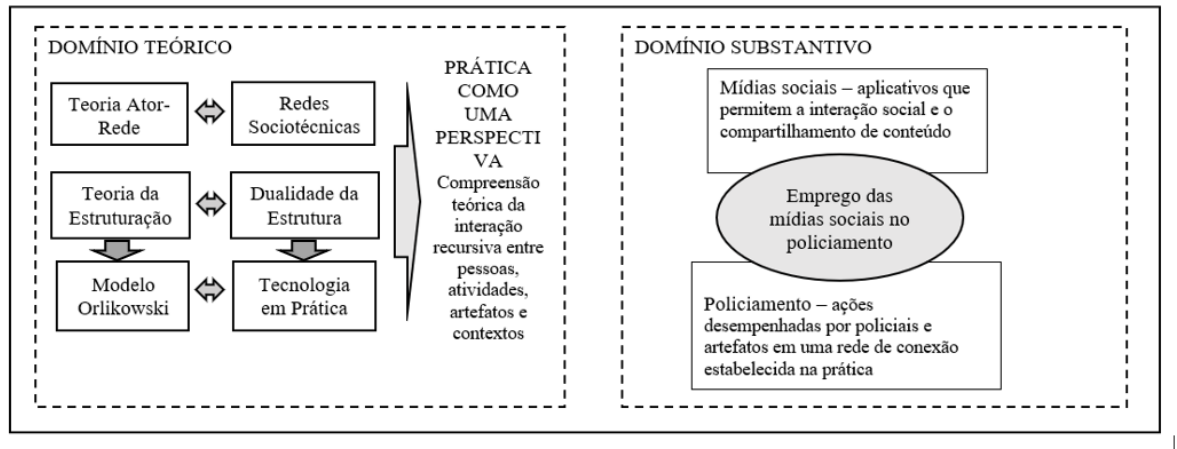

FIGURA 1

Quadro teórico de referência

Fonte: Elaborado pela autora.

\section{PROCEDIMENTOS METODOLÓGICOS}

Nesta pesquisa, optou-se por realizar uma investigação qualitativa interpretativista (Creswell, 2014), pois nessa perspectiva a realidade é socialmente construída. A metodologia utilizada foi o estudo de caso construtivista (Langley \& Abdallah, 2011) e instrumental (Stake, 2005), focalizando uma questão específica em relação ao fenômeno ao invés do caso em si. Esse método é apropriado quando a atividade é o objeto de análise e se busca articular teorias da prática para a compreensão do fenômeno que se quer investigar. As facilidades de acesso e rapport definiram a PM objeto deste estudo, tendo em vista que uma das autoras trabalhou por 28 anos nessa força policial. A seleção do caso se deu após a leitura de um diagnóstico sobre o uso do Facebook nessa instituição, realizado em 2015.

A coleta e a análise dos dados ocorreram entre outubro de 2016 a setembro de 2018. A alteração no foco da questão de pesquisa, inicialmente na tecnologia enquanto artefato em 2016, e posteriormente como tecnologia em uso a partir de 2017, foi responsável pelo longo período de coleta e análise. Esse processo não ocorreu como uma sequência encadeada de fases, pois, os instrumentos de coleta de dados - observação participante, entrevistas e documentação -, redirecionaram por diversas vezes o curso da pesquisa. Essas múltiplas fontes e métodos de dados e o envolvimento prolongado no campo garantiram a triangulação dos dados e o rigor na pesquisa (Creswell, 2014).

Entre outubro e dezembro 2016, foram feitos levantamentos documentais e realizadas oito entrevistas não estruturadas com policiais da Diretoria de Comunicação Organizacional (DCO) sobre o uso do Facebook pela PM. Esses dados foram apresentados em um Paper Development Workshop, em abril de 2017, e em um Fórum Acadêmico, em agosto de 2017. A incorporação das críticas recebidas nesses eventos reorientou a questão de pesquisa. Entre setembro e dezembro de 2017, foram realizadas 20 entrevistas semiestruturadas com policiais que atuavam no nível tático: Diretoria de Apoio Operacional (DAOp), Diretoria de Tecnologia e Sistemas (DTS), Diretoria de Inteligência (DInt) e Corregedoria (CPM) sobre o uso das MS pela polícia e no policiamento. Entre janeiro e maio de 2018, realizou-se observação participante nas viaturas e em operações policiais de um Batalhão (em dias e horários alternados), e nove entrevistas semiestruturadas com policiais operacionais, com o mesmo objetivo das entrevistas realizadas com o(a)s 
policiais do nível tático. Todo(a)s o(a)s entrevistado(a)s leram e assinaram o Termo de Consentimento Livre e Informado. As entrevistas foram anonimizadas com um código-participante (PM + numeral). O(a)s participantes tiveram acesso à transcrição de suas entrevistas para conferência e validação e nenhum dele(a)s solicitou alterações. O projeto de pesquisa foi submetido ao Comitê de Ética da Fundação Getúlio Vargas e obteve autorização da PM para realização dos trabalhos de campo.

No tratamento dos dados, foram combinadas as estratégias de narrativa (Langley, 1999; Fenton \& Langley, 2008) e de codificação (Corley \& Gioia, 2004; Strauss \& Corbin, 2008). A estrutura narrativa teve papel fundamental tanto para orientar a coleta de dados no período de observação direta e entrevistas, quanto para o processo posterior de codificação, tornando compreensível as sequências nos níveis de análise e as ligações entre os níveis e estabelecendo os primeiros temas analíticos (Langley, 1999). O tratamento teve início por meio da codificação aberta, na qual os conceitos iniciais são identificados em trechos destacados nas respostas dadas pelos participantes nas entrevistas, nas notas de campo e na documentação, e agrupados em categoriais (códigos) por meio de uma frase simples descritiva (Corley \& Gioia, 2004; Strauss \& Corbin, 2008), com auxílio do software Atlas TI. Esses códigos foram relacionados a um conceito de primeira ordem (Corley \& Gioia, 2004) e, a partir da identificação das relações entre esses conceitos, estabeleceu-se os temas de segunda ordem, agregados posteriormente em dimensóes. Nesse processo foram identificados 55 códigos, 10 conceitos de primeira ordem, 5 temas de segunda ordem e 2 dimensões agregadas.

\section{APRESENTAÇÃO DOS DADOS E ANÁLISE DOS RESULTADOS}

Os conceitos, os temas e as dimensões que emergiram no processo de análise dos dados são detalhados a seguir, a partir dos temas de segunda ordem que contribuíram para que se respondesse de que maneira e com que finalidade as MS são empregadas no policiamento.

\subsection{Mídias sociais como fonte aberta de dados}

A velocidade de processamento, o acesso a um grande volume de dados, o manuseio fácil e o amplo alcance, estão entre as características mais destacadas nas entrevistas e, em conjunto com a rapidez e a quantidade de dados transmitidos, contribuem significativamente nas atuações dos policiais. Esses atributos das MS definem a eficácia na resposta policial.

O que antes demorava um largo espaço de tempo para ele [policial] tomar conhecimento... agora é imediato. Agora, surgiu o fato ali, já lança aquilo ali” (PM9). A velocidade com que a informação chega e é trabalhada determina o sucesso ou o fracasso de alguma medida (PM9).

Essa narrativa foi frequente nas entrevistas: podemos chegar mais rápido e assim prender mais infratores. Em alguns casos, são necessários poucos compartilhamentos e troca de informações para que o plano de bloqueio e interceptação seja acionado, o cerco feito e o(a) suspeito(a) do crime preso.

Alguns participantes (PM12, PM18 e PM25) percebem que as MS apenas reforçam as práticas tradicionais de policiamento aleatório, contribuindo para diminuir o tempo de resposta às chamadas de serviço e aumentar as possibilidades de prisóes. $\mathrm{O}$ aprimoramento da tecnologia policial como um meio de controle do crime não é um fato novo para a polícia (Manning, 2003).

As MS têm representado, para a relação tempo-espaço no atendimento às ocorrências, mais agilidade e eficácia do que as viaturas e os rádios no século $\mathrm{XX}$, o que não significa dizer que a polícia se tornou menos reativa (Crump, 2011). A finalidade última ainda é a eficiência por meio do combate à criminalidade. Pouco(a)s participantes abordaram as possibilidades das MS para o policiamento preventivo e preditivo (PM18, PM27 e PM28). "O uso que é feito dos dados é capaz de evidenciar muito sobre a estratégia e as práticas da polícia” (Davis, Alves \& Sklansky, 2014, p. 2). 
A polícia pode usar os dados para facilitar o ajuste das políticas às necessidades e demandas da(o)s cidadã (o)s, o que pode resultar em maior capacidade de resposta. Nessa direção, o foco para o emprego das MS seria a comunidade, e não os indivíduos que praticam crimes. Essa utilização das MS possibilitaria à PM atuar menos apoiada e dependente do sistema de emergência, em que a polícia é acionada durante a ocorrência do delito ou depois de o mesmo ter sido consumado (Manning, 2003). Acredita-se que seja uma forma de prevenção mais eficiente.

Nas polícias estadunidense e europeias, as pesquisas revelaram as contribuições que o volume e a velocidade de transmissão de dados possibilitam, que vão desde a localização de feridos/necessitados de ajuda em catástrofes e de suspeitos em atentados (Davis, Alves, \& Sklansky, 2014), até a colaboração da população em casos de investigação (Trottier, 2012). Observou-se que na PM, especificamente, esses atributos contribuem para o levantamento de informações no Facebook. Não que esse levantamento não ocorra naquelas polícias (Trottier, 2015). Aliás, nas MS o policiamento se desfaz da sua principal característica: a ostensividade pela qual o(a) policial pode ser identificado(a) de relance pela farda, apetrechos e armamento.

Essa fonte aberta de dados disponibilizada pelas MS representa uma ameaça à centralização da informação e à racionalidade na orientação das ações policiais, que sempre foram realizadas pelos Centros de Operação, seguindo e respeitando a cadeia hierárquica. As MS possibilitaram a um(a) policial do menor município, receber simultaneamente e em tempo real, as mesmas informações que são repassadas para o(a) Comandante Geral da PM. Dependendo do fato, isso tem um impacto significativo para a solução que será dada. Com as MS, tem sido necessário um comando mais participativo. No próximo item, apresentam-se as finalidades identificadas para o emprego das MS na Polícia Militar.

\subsection{Para que as mídias sociais são empregadas no policiamento}

\section{O emprego das midias sociais na comunicação institucional}

O potencial para interação social proporcionado pelas MS, tem levado a polícia a adotar essas ferramentas tecnológicas para manter os laços existentes criados "ao vivo" nas Redes de Vigilância e Proteção e para atrair grupos não envolvidos anteriormente na discussão do policiamento local (Lieberman, Koetzle, \& Sakiyama, 2013; Davis, Alves, \& Sklansky, 2014). Os grupos têm se proliferado no WhatsApp, pois a criação deles foi bastante simplificada. "Você cria lá: Rede de Vizinhos, Rede de Comerciantes, Rede de Escolas, Rede de Indústrias, Rede de Bancos" (PM11). Há ganhos significativos quando é preciso amplo alcance e rapidez no repasse das informações, mas perde-se muito no contato entre os locais e entre estes e a polícia (PM11; PM23).

No entanto, esses grupos têm reduzido a confiança que o(a)s policiais deveriam ter em relação a $(o) s$ civis participantes dessas redes, pois, muitos grupos não adotam providências rígidas para inclusão e manutenção do(a)s participantes. Os riscos com a segurança pessoal para o(a)s policiais, nesses grupos, são reais. A exposição do(a) policial nas diversas redes foi um comentário recorrente nas entrevistas. "Da mesma forma que a gente tem acesso às redes sociais, os infratores também têm. Então, pode ser um caso de vulnerabilidade da vida cotidiana desse policial" (PM16). O(a)s policiais alegaram que o número fornecido nesses grupos é o número do celular pessoal e que pode ser repassado para pessoas que não fazem parte da rede. Por precaução, alguns adquiriram smartphone com dois chips, sendo um para os assuntos funcionais da PM e outro para assuntos pessoais (PM34 e PM30).

Observou-se que, para o(a)s policiais que atuam na Comunicação Institucional, as MS, em especial o Facebook, são plataformas nas quais a interação com a sociedade vem ocorrendo (Lieberman, Koetzle, \& Sakiyama, 2013). Essa visão é corroborada pelo(a)s participantes das demais diretorias. O que se depreende é que o Facebook é a mídia da polícia, na direção de resguardar uma boa imagem, divulgando as ações que na maioria dos casos as mídias tradicionais não publicam ou transmitem (PM6, PM7, PM9, PM13, PM14, PM19, PM20). Não se sabe ao certo qual é o público que interage com o Facebook da PM. As pesquisas que 
de alguma maneira buscaram responder a essa indagação em outras polícias, concluíram que a proporção de usuários é bastante baixa (Lieberman, Koetzle, \& Sakiyama, 2013; Brainard, \& Edlins, 2015).

Entre o(a)s participantes, menos de $10 \%$ disseram seguir a página da polícia ou conhecerem pessoas que o façam (PM1, PM5 e PM6), e vário(a)s relataram não possuir um perfil no Facebook, alguns por razões de segurança (PM13, PM20, PM21 e PM23), outro(a)s por desinteresse nas funcionalidades que o site disponibiliza (PM8 e PM27); para o(a)s policiais mais novos, "o Facebook caiu em desuso, hoje nós utilizamos o Instagram. Eu sigo o 48 BPM pelo Instagram” (PM33).

A Imagem Institucional, dimensão relacionada ao tema Comunicação Institucional, é destacada como uma das principais finalidades do uso das MS pela PM, indo ao encontro dos achados da revisão de literatura, provavelmente, por ser a interação social uma característica intrínseca desses artefatos. Estudiosos procuram compreender a conexão en tre os atributos das MS e as finalidades do policiamento comunitário (Davis, Alves, \& Sklansky, 2014; Grimmelikhujisen \& Meijer, 2015; O’Connor, 2015).

Diversas narrativas que destacavam a Imagem Institucional tratavam da controvertida situação da filmagem por policiais ou por civis das atuações policiais, em especial nas que demandam o uso da força. Os smartphones favorecem esse registro em áudio e vídeo, pode-se gravar e distribuir por meio do WhatsApp ou de outras MS antes mesmo que o comando ou as mídias tradicionais tenham conhecimento dos fatos (PM1, PM5, PM13). As gravações dos policiais em ação são descritas por meio de duas óticas divergentes, relacionadas aos sujeitos que as realizam. Quando se trata do(a)s policiais gravando suas atuações, as falas sinalizam: (i) garantia de transparência e lisura da ação policial (PM4, PM15, PM16 e PM21), principalmente, nas ações em que haja o uso da força (PM15, PM17, PM18); (ii) divulgação e autopromoção de alguns policiais em suas redes sociais (PM24). Quando se trata de civis gravando as atuações, as narrativas revelam se tratar de uma forma de intimidação à ação policial. Independentemente dos sujeitos, há uma compreensão de que as gravações contribuem para a redução de práticas à margem da lei e do emprego imoderado do uso da força. Por outro lado, constata-se que os smartphones e as MS impuseram à polícia a perda do controle relativo à divulgação de imagens negativas.

O emprego das mídias sociais na comunicação interna

A comunicação interna trata das redes formais e informais, dos fluxos informativos e das barreiras existentes no interior da instituição. A MS mais utilizada na comunicação interna na PM tem sido o WhatsApp. Há "uma Intranet que deve ser acessada, pelo menos duas vezes por dia, durante o turno de serviço, no dia em que o policial está escalado” (PM22), mas o(a)s policiais acessam com maior frequência o WhatsApp, chegando em algumas situações a usar o aplicativo para retransmitir ordens e mensagens postadas na Intranet (PM21, PM22). Pode-se verificar que esse aplicativo foi absorvido pelas redes formais. O fluxo informativo de escalas de serviço, planos de operação, anúncios de turno, dentre outras mensagens institucionais, seguem primeiro pelos grupos de WhatsApp e, posteriormente, pela Intranet. "Por exemplo, operação que a gente vai desencadear aqui na cidade [...]. A gente já transmite aquela informação no grupo, basicamente o Whats $A p$, apesar que a gente usa a intranet também, mas é aquela informação instantânea" (PM10).

Há uma rede institucional que é bastante utilizada pelo Comandante Geral para transmissão de mensagens. "Nós temos alguns... na verdade, a rede, a PM, ela tem uma rede, falando de WhatsApp, ela tem uma rede institucional. Primeiro criada nos telefones funcionais. Todos os comandantes, até o nível de Companhia Independente, têm o telefone funcional" (PM23).

A utilização dos grupos de WhatsApp como uma rede formal tem suscitado discussões sobre a legalidade das ordens transmitidas por esse canal. "Só tem um ponto negativo, que o WhatsApp acabou em alguns locais sendo institucionalizado, de forma informal” (PM22). O(a)s participantes PM22 e PM24 questionaram esse uso formal do aplicativo, considerando a não regulamentação do mesmo. "Então a instituição não consegue forçar uma pessoa a utilizar” (PM24). "Então, aí, vamos dizer, o subordinado tem a obrigação, realmente, de 
participar do grupo de WhatsApp que foi criado pelo Chefe? Tá vendo? Acaba institucionalizando uma coisa que não é para ser institucionalizada" (PM22).

Mesmo não sendo um canal de informação oficial, as normas às quais estão submetidos os policiais são empregadas nos grupos de Whats $A p p$ das Unidades. "Tem normas, a gente não pode postar qualquer coisa. Tem a forma, o regulamento. A gente aplica o regulamento no grupo de WhatsApp. Com certeza" (PM21). Além disso, a cadeia de comando precisa ser seguida, mas "a gente tenta furar" (PM21). Segundo normas internas, o(a)s policiais não podem se dirigir indistintamente aos superiores. "Aquela regra da PM, que falava assim: procura seu chefe direto. Depois, se ele te autorizar você procura... A cadeia de comando, sabe. Ela está fragilizada com a mídia" (PM23). As MS “estão colocando à prova o controle e a exposição de formas tradicionais de autoridade, questões de honra e a manutenção de sistemas de estratificação diferenciada" (Manning, 2003, p. 419).

O emprego das midias sociais para redução de lacunas de informação

A narrativa de um participante que ingressou na PM na década de 90, para descrever o acesso à informação àquela época e hoje, mostra a importância das MS para redução da falta, da falha, da interrupção e do não acesso às informações para os policiais lançados no policiamento.

Antigamente, antes dessa comunicação das MS, a gente se limitava a usar, no caso, o telefone público. Eu me lembro que andava com ficha de telefone no bolso, em questão de prioridade para ligar no quartel, porque às vezes o 190 não atende (PM31). Para conseguirem uma informação mais imediata era necessário que o(a)s policiais portassem em papel as normas nas quais estavam registradas orientações para atuação (PM31).

Identificar, nesta pesquisa, como se dá a metodologia de processamento e obtenção dos dados por meio das MS, possibilitou compreender o porquê de o Whats App e os aplicativos desenvolvidos para segurança pública serem determinantes para a redução das lacunas de informação na tomada de decisão localizada. Essas MS possibilitam o acesso imediato a fontes de consulta para esclarecer dúvidas e validar as ações para o combate à criminalidade (PM16, PM18, PM33 e PM34).

As MS têm um papel importante para o reconhecimento imediato de suspeitos. "Alguém na rede de rádio: esse menino, como é esse menino, estou achando que é o mesmo que assaltou ontem a fulana de tal” (PM27). Antes das MS, o policial descreveria na rede de rádio as características do abordado: altura, cor da pele e dos cabelos ou algum traço que pudesse identificá-lo. As MS permitem uma troca de informações visuais mais qualificadas do que somente a descrição verbal. É possível transmitir fotos, vídeos, voz. "Isso representa um ganho muito grande em relação à própria atividade policial” (PM27). Mas, Trottier (2012, 2015) adverte sobre os cuidados necessários com os limites legais nesse uso.

Os grupos formados pelos policiais no WhatsApp proporcionam a troca de dados e a discussão sobre mudanças na legislação e dos casos em que há falhas na atuação policial. Nas entrevistas, um fato narrado por diversos participantes pode exemplificar a importância das MS para a aprendizagem na polícia. Trata-se do assassinato de uma mulher pelo ex-marido dentro de uma viatura. O casal era levado para a delegacia, após uma denúncia da vítima de estar sendo filmada no banheiro de sua casa, quando, quase ao final do trajeto, o homem retirou uma faca do tênis e golpeou a ex-esposa. Isso não teria ocorrido se o conduzido tivesse passado por uma busca pessoal antes de entrar na viatura, conforme previsto no protocolo policial. Essas situações, embora trágicas, possibilitam a(o) policial "pensar duas vezes antes de cometer o mesmo erro" (PM21). Não só o(a) policial, mas também, a polícia: "então a Instituição, com certeza, a primeira coisa que ela vai se preocupar é que isso não venha a ocorrer de novo. Ela não quer que isso ocorra de novo” (PM13).

Para realizar o seu trabalho, a polícia necessita obter, processar, decodificar e usar diversos tipos de informação que são utilizadas para diferentes fins (Manning, 2003). As narrativas evidenciam que as MS têm contribuído para que as informações sejam mais bem qualificadas, e isso é fundamental para a tomada de decisão. Manning (2003, p. 378) entende que, nesse processo, "o(a)s policiais se orientam por pressupostos, baseados no senso comum, a respeito de seu trabalho, de sua atuação principal e nas expectativas da comunidade". Ou seja, as informações são mais qualificadas, mas empregadas de maneira análoga à ocorrida 
antes das MS. A alegação de Manning (2003) pode ser aceita em parte. As informações são empregadas, em sua maioria, para o combate à criminalidade, mas a visibilidade dada às atuações tem exigido dos policiais que as técnicas sejam mais bem empregadas, pois isso repercute na Imagem Institucional.

As falhas e os acertos em atuações transmitidas e discutidas por meio das MS, têm tido um papel relevante para que o(a) policial aperfeiçoe suas habilidades. Os grupos formados pelo(a)s policiais no WhatsApp proporcionam não só o intercâmbio de dados, mas discussões que contribuem para a aprendizagem. Nesse sentido, as MS podem ser ferramentas para o compartilhamento de conhecimento dentro das organizações policiais (Crump, 2011). Além disso, esse processo favorece a construção de identidades em relação a essas comunidades, pois, participar de uma comunidade, de uma equipe de trabalho ou grupo de MS, molda não apenas o que esse(a)s policiais fazem, mas também, quem são e como interpretam o que fazem. Esse sentido de pertença contribui para o fortalecimento do espírito de corpo, abordado no próximo subitem.

O emprego das midias sociais para o fortalecimento do espirito de corpo

As MS funcionam como um amálgama por possibilitar a(o)s policiais, por meio do contato, independentemente da distância geográfica ou do posto/graduação, se manterem unido(a)s e colaborativo(a)s uns com o(a)s outro(a)s para o cumprimento da missão de combate ao crime. Em uma narrativa, um participante relatou que o efetivo na PM diminuiu em quantidade de pessoas, mas a percepção é de que tenha aumentado em razão das MS. "Hoje na MS eu posso estar sozinho na viatura, eu deparei com uma pessoa em atitude suspeita, eu lanço no grupo do CPU, eu lanço no grupo da Companhia, rapidinho chega apoio para mim" (PM31).

$\mathrm{O}(\mathrm{a})$ s policiais participam de vários grupos que estão interligados em diversas redes. "Por mais que a gente não queira, a gente tem vários grupos de polícia. Grupo de turma, grupo de curso, grupo de unidade, grupo de estudo" (PM13). Isso faz com que o(a)s policiais possam estar geograficamente distantes, mas se relacionando com frequência. "Então, acaba tendo algumas ocorrências que a mídia nem divulgou, mas tem colegas nossos envolvidos na ocorrência e eles passam detalhes da ocorrência para a gente" (PM13). Uma participante relata que isso se torna um ciclo de informação, no qual é possível ter ideia do todo. As MS possibilitam que os laços construídos no período de formação, ou de contato profissional servindo em alguma unidade, sejam mantidos, independentemente das distâncias ou de mudanças de posto/graduação (PM21).

Entretanto, essa aproximação acaba se tornando um risco para a adoção de medidas com um baixo índice de aceitação vindas do governo ou do comando, ou ainda para matérias que beneficiem apenas determinados setores da polícia. Isso em razão de os grupos de Whats $A p p$ permitirem a $(\mathrm{o})$ s policiais se articularem por posto ou graduação, por local de trabalho, por turma em que se formou ou mesmo pela PM.

No próximo subitem, distingue-se a dimensão agregada Combate à Criminalidade. As pesquisas que não se aproximaram do(a) policial em sua atuação diária para investigar a utilização das MS identificaram somente a dimensão Imagem Institucional. Pode-se pensar que, nesses estudos, a imagem institucional incorpore o controle da criminalidade, pois partem do pressuposto de que o emprego das MS proporciona mais interação social e eficácia, que podem ser retratadas em fotos, vídeos e textos nas MS. A lente da prática proporcionou visualizar as duas faces das narrativas - da instituição e do(a) policial - e evidenciou como as fontes abertas de dados concorrem para trazer à tona estruturas que coexistem com o combate à criminalidade, finalidade última para o uso das MS no policiamento.

\section{A Dimensão Combate à Criminalidade}

Esta dimensão agrega os temas de segunda ordem: (i) fonte aberta de dados; (ii) comunicação interna; (iii) redução de lacunas de comunicação; e (iv) fortalecimento do espirito de corpo. Em conjunto com a dimensão Imagem Institucional, representa uma das duas faces do discurso policial: proteger os cidadãos e combater o crime. Nas narrativas, é possível visualizar esse duplo potencial das MS. No entanto, há participantes que entendem que esse uso é limitado diante das oportunidades que essas ferramentas oferecem (PM12, PM18 e PM27). 
Para o participante PM27, as MS vêm alterando o policiamento de maneira modesta, pois a PM usa, intencionalmente, muito pouco as redes sociais a seu favor, mesmo para a gestão organizacional. Para ele, as relações interpessoais foram as mais impactadas na polícia. "E diante de uma cultura organizacional forte como a nossa, isso tem influência. Otimizou tanto a relação entre as pessoas, que você vê a cultura organizacional sendo transformada com essa ferramenta" (PM27). Ele conclui dizendo que, para combater o crime, as MS são subutilizadas "diante dos potenciais, das possibilidades de utilizar isso a favor do combate à criminalidade".

Para Manning (2003), toda a complexidade que envolve o policiamento faz com que o(a)s policiais recorram à substitutos indiretos, como tempo de resposta, número de prisões e de crimes registrados, à parcerias e mais interação com a comunidade. Para isso, as MS se adequam perfeitamente, pois possibilitam $\mathrm{a}(\mathrm{o}) \mathrm{s}$ policiais prosseguirem com suas abordagens tradicionais com foco no crime, ao mesmo que tempo em que favorecem os programas e as parcerias orientadas para a comunidade, tais como as Redes Virtuais de Proteção.

Apesar de serem quase sempre ressaltadas as capacidades "idílicas” das MS para a interação, é preciso estar atento ao sentido dado a essa interação em razão das implicações éticas e do comprometimento da confiança. Tal como acontece com as estratégias de "stealth marketing" praticadas por algumas empresas por meio das MS, nas quais um produto é anunciado de maneira subliminar com o objetivo de tornar as pessoas interessadas no produto apresentado, a verdadeira interação buscada pela polícia com a(o) cidadã(o) pode não estar clara ou estar encoberta por envolver a intrusão e/ou a exploração das relações sociais como meio de alcançar a eficácia, comprometendo seriamente a sua legitimidade (Davis, Alves, \& Sklansky, 2014). No caso específico da polícia, isso pode ocorrer, também, em razão da importância dada à opinião pública e do controle que exerce sobre essa organização (Bayley, 2001). Uma síntese desta análise dos dados está retratada na Figura 2. A TE e a TAR foram lentes poderosas para explicar o fenômeno do uso das MS no policiamento.

\section{DISCUSSÃO DOS RESULTADOS}

A lente da prática favoreceu a explicação sobre a forma e a finalidade do uso desses artefatos tecnológicos. Primeiro, ao contrário do que afirmou Manning (2003, p. 419) sobre a centralização da informação, observou-se que através do Whats $A p p$ as informações são dispersadas. Isso se dá em razão do volume e da velocidade com que as informações são produzidas, do alcance que possibilitam e do interesse do policial em manter aquele dado disponível para uso futuro, em um banco pessoal no seu smartphone. Essa dispersão redunda em diversos bancos de dados criados e replicados pelas frações policiais e por grupos de policiais. Essas funcionalidades, efetivamente consideradas pela agência, representam os recursos. Essa é uma tendência que merece atenção, pois impacta diretamente a coordenação e o controle exercidos por meio da cadeia de comando. 


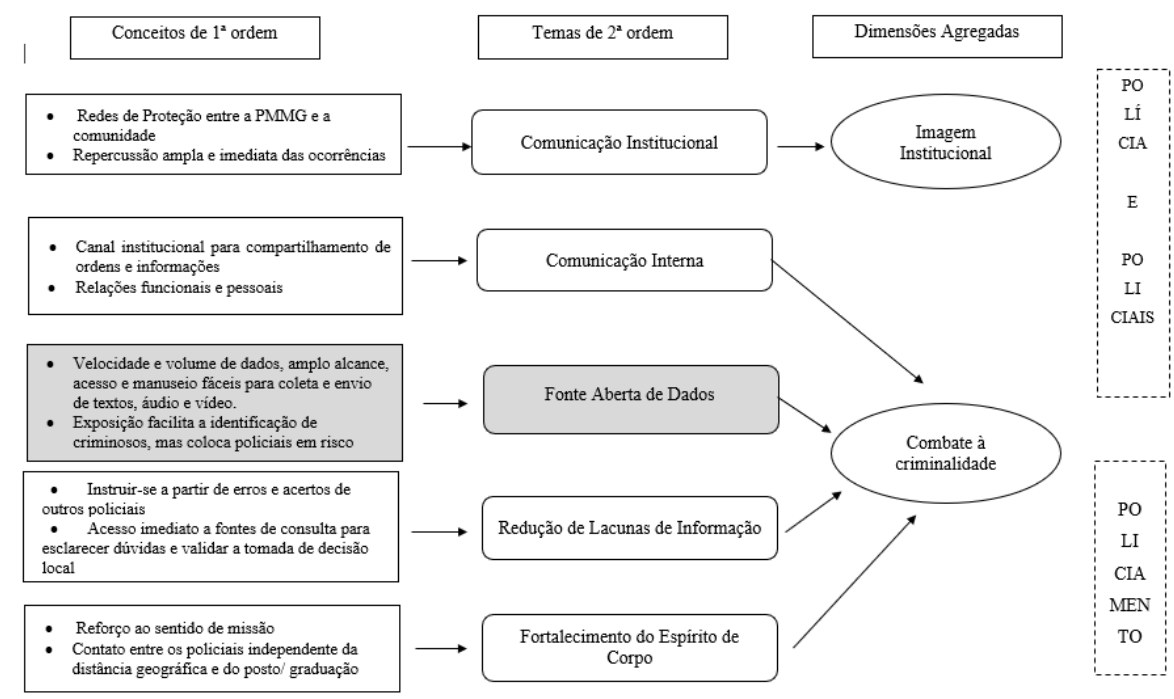

FIGURA 2

Síntese da análise sobre como e para que as MS são empregadas no policiamento Fonte: Elaborado pela autora segundo Corley e Gioia (2004, p. 184).

Indo ao encontro das discussões de Giddens (2009) e Orlikowski (1992, 2000) sobre a dualidade da estrutura, constatou-se que padrões culturais e de ação e outras normas que cuidam da disciplina e da hierarquia (propriedades estruturais do sistema) e que mantêm a cadeia de comando, são empregadas como forma de legitimação. Assim, é possível visualizar o mecanismo de forças entre recursos e normas atuar sobre o esquema interpretativo por meio do qual o(a)s policiais dão sentido às MS e aos recursos oferecidos por esses artefatos na execução do policiamento, reforçando ou mudando seus pontos de vista e experiências em um processo contínuo e recíproco.

Os conteúdos criados, replicados e transmitidos por meio das MS servem de base para o processo de interpretação do(a)s policiais (esquemas interpretativos). Por meio desses esquemas, o(a)s policiais dão sentido à tecnologia e aos recursos oferecidos por ela e transformam a estrutura cognitiva gerada pelo seu próprio uso, o que poderá reforçar ou mudar suas opiniões e experiências em um processo contínuo e recíproco, como no modelo proposto por Orlikowski (2000). Os esquemas interpretativos utilizados pelo(a)s policiais, baseiam-se nas funcionalidades do WhatsApp, dos aplicativos de segurança pública e na premissa de que a velocidade e o alcance de transmissão da informação, por meio dessas ferramentas tecnológicas, serão úteis para a diminuição do tempo de resposta aos chamados, o que aumenta a eficácia no combate ao crime.

A significação gerada a partir dos esquemas utilizados pelo(a)s policiais para interpretar e situar o uso que fariam das MS no policiamento, em especial o WhatsApp, deu origem à estrutura combate à criminalidade, marcada pelo uso intensivo das funcionalidades para: (i) consultas e compartilhamento de informações; (ii) agilizar e assegurar a tomada de decisão local; (iii) aprimorar a qualidade das soluções; e (iv) disseminar o conhecimento entre os membros dos grupos. Adicionalmente, outras estruturas identificadas que evidenciaram a capacidade de influência no emprego do uso das MS no policiamento, contribuindo positivamente para que o combate à criminalidade seja atingido pelo(a)s policiais e pela $\mathrm{PM}$, foram: (i) comunicação interna; (ii) redução de lacunas de informação; e (iii) fortalecimento do espírito de corpo.

Dentre as associações decorrentes dos vínculos (redes de atores heterogêneos) entre policiais (bumanos) e artefatos tecnológicos (não humanos), aqui compreendidas as MS, os aplicativos desenvolvidos para segurança pública, os sites, os smartphones, foi possível identificar, principalmente, ao aproximar da questão geracional e da relação entre superior-subordinado, os efeitos dos vínculos dos policiais entre si, os artefatos em si e dos policiais e artefatos entre si como proposto na TAR (Latour, 1999). Os efeitos visíveis estão na melhoria das relações interpessoais com mais envolvimento entre os graduados e os oficiais, 
independentemente da distância geográfica ou do local de trabalho em que se encontrem. No entanto, essa aproximação pode resultar em um efeito reverso para estratégias de policiamento preventivo e proativo. O reforço ao sentido de missão e o fortalecimento do espírito de corpo são um estímulo para as práticas tradicionais de policiamento aleatório, com ênfase na redução do tempo de resposta e na prisão de infratores.

Os grupos de WhatsApp representam bem o conjunto de associações possíveis no processo de construção das redes sociotécnicas entre policiais e artefatos, que a TAR define como translação (Callon, 1986; Latour, 1999). A rede aqui é considerada tanto o meio quanto o resultado das interações, e recursiva e precariamente gera e reproduz interações posteriores. Em sua maioria, esses grupos nos quais ocorrem as interações são abertos e possibilitam diversos tipos de conexão, o que favorece o crescimento para qualquer direção, cuja extensão e composição são sempre contingentes, não sendo de natureza exclusivamente técnica ou social. Esse modelo do uso das mídias sociais no policiamento pode ser visualizado na Figura 3.

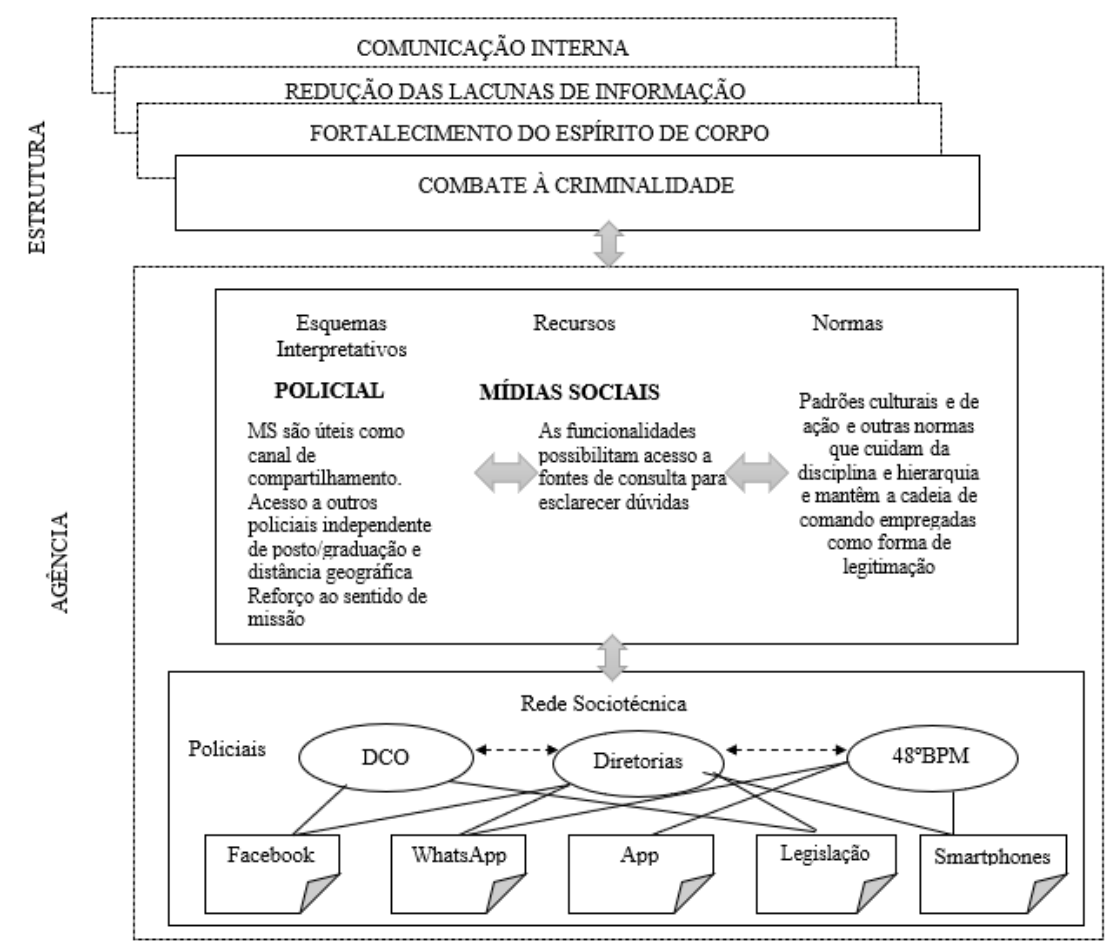

FIGURA 3

Modelo do uso das mídias sociais no policiamento Fonte: Elaborado pela autora.

\section{CONSIDERAÇÕES FINAIS}

Este trabalho ampliou o conhecimento disponível sobre mídias sociais em uma Polícia Militar do Brasil, explicando a forma e a finalidade com que esses artefatos tecnológicos são empregados no policiamento sob a lente da prática. Para isso, inicialmente, buscou-se identificar os tipos e as funcionalidades das MS utilizadas na prática policial. Nessa direção, o WhatsApp e os aplicativos desenvolvidos para a segurança pública por órgãos governamentais, pela Polícia Militar e por policiais, são as mídias sociais mais usadas. As funcionalidades dessas MS mais destacadas nas narrativas foram: (i) a velocidade e o volume de dados; (ii) o amplo alcance; e (iii) o fácil acesso e manuseio para coleta e envio de textos, áudios e vídeos. Essas características permitem a $(\mathrm{o}) \mathrm{s}$ policiais compartilharem informações e terem acesso imediato a fontes de consulta para esclarecer dúvidas e validar a tomada de decisão local. $\mathrm{O}$ uso associado e sincrônico do 
WhatsApp com os aplicativos (QApp, Sinesp, QAP Multas, Infra Note) aumenta a capacidade de resposta aos chamados de emergência e a redução do tempo de chegada e resolução de conflitos pelo(a)s policiais.

Em continuidade, identificou-se como as regras e os recursos estruturam o uso das MS no policiamento. Enquanto fonte aberta de dados, as MS são apropriadas pelo(a)s policiais como recursos que lhes conferem poder na tomada de decisão. No entanto, em algumas situações, os dados são obtidos e empregados sem obediência à cadeia de comando, sem se atentar às regras estabelecidas. Para que essas regras sejam seguidas e para que o lócus do poder vigente seja mantido, a polícia aplica sanções aos transgressores em uma tentativa de limitar a capacidade de decisão auferida pelas informações obtidas através das MS.

Finalmente, explicitou-se a contribuição de uma abordagem baseada na prática para o entendimento do emprego das MS em organizações policiais. Aproximar-se do(a)s policiais envolvidos diariamente na prática policial, desvenda situações muitas vezes desconhecidas para os policiais que atuam no nível estratégico ou que não estão diariamente nas ruas. As pesquisas que tratam do uso das MS pela polícia têm focalizado as entrevistas com o(a)s policiais que atuam no nível estratégico como as principais fontes de dados. Em direção contrária, a lente da prática permitiu explicar que as midias sociais são utilizadas no policiamento como fonte de dados para o combate à criminalidade e para o fortalecimento da imagem institucional.

Como contribuições para a literatura, nesta pesquisa identificou-se que as características mais destacadas para o emprego das MS no setor público e, em especial, pela polícia, são a interatividade (Kaplan \& Haenlin, 2010; Crump, 2011; Davis, Alves, \& Sklansky, 2014; Brainard \& Edlins, 2015) e a disponibilidade de dados (Trottier, 2012, 2015). Esses atributos influenciam as relações de dependência e autonomia entre atores humanos e não humanos. Os estudos sobre MS e polícia se concentram em casos de polícias estadunidenses (Manning, 2005) ou europeias. Esta pesquisa cobre um gap, investigando um caso do uso das MS em uma Polícia Militar no Brasil.

O policiamento comunitário é a estratégia para a qual se voltam as pesquisas para explicar o uso das MS pela polícia. No entanto, nem o policiamento comunitário nem as MS se mostraram estratégias eficientes para aumentar a participação, o engajamento e a legitimidade da polícia junto à comunidade. Esta pesquisa descreve que as fontes abertas de dados intensificam o sentido de missão e o espirito de corpo em direção às práticas reativas do policiamento tradicional.

Dentre as implicações para a prática, o trabalho contribuiu com informações que subsidiam uma melhor instrumentalização das polícias militares e com o incentivo ao debate acadêmico voltado ao emprego das MS nessas organizações.

Investigações sobre a influência das MS para a aprendizagem social na polícia, constituem um tópico relevante para investigações futuras. Pesquisas que analisem se e de que maneira o Whats $A p p$ reforça a cultura e subculturas policiais, serão uma contribuição significativa para esse campo. O papel da teoria no design e na estratégia de pesquisa constitui, também, uma oportunidade para estudos futuros, pois o número de artigos com uma contribuição teórica para o campo é pouco significativo. Não foi detectada na revisão de literatura sobre o uso de MS e polícia, abordagens sob a perspectiva do big data, considerado o número expressivo de informações geradas pelas MS. As narrativas sobre punições, em razão do conteúdo postado pelo(a)s policiais, tratam apenas das críticas formuladas ao Comando ou ao Governo. Nada se falou sobre postagens que desrespeitem direitos constituídos ou que incitem a prática de crimes, que foram a tônica das eleições presidenciais de 2018 no Brasil. Também estudos nessa direção serão uma contribuição efetiva.

\section{REFERÊNCIAS}

Bayley, D. H. (2001). Padrões de policiamento. São Paulo: Edusp.

Brainard, L., Edlins, M. (2015). Top 10 US municipal police departments and their social media usage. The American Review of Public Administration, 45(6), 728-745. 
Callon, M. (1986). Some Elements of a Sociology of Translation-Domestication of the Scallops and the Fishermen of St-Brieuc Bay. In J. Law (Ed.) Power, Action and Belief: A New Sociology of Knowledge?, (pp.196-223). London: Routledge,

Corley, K. G., Gioia, D. A. (2004). Identity ambiguity and change in the wake of a corporate spin-off. Administrative science quarterly, 49(2), 173-208.

Cotta, F. A. (2006). Breve história da polícia militar de Minas Gerais. Belo Horizonte: Crisálida.

Creswell, J. W. (2014). Investigação Qualitativa e Projeto de Pesquisa: escolhendo entre cinco abordagens. Porto Alegre: Penso Editora.

Crump, J. (2011). What are the police doing on Twitter? Social media, the police and the public. Policy \& Internet, $3(4), 1-27$.

Davis, E. F., Alves, A. A., Sklansky, D. A. (2014). Social media and police leadership: Lessons from Boston. Australasian Policing, 6(1), 10.

Fenton, C., Langley, A. (2008). Strategy as Practice and the Narrative Turn. Les cabiers de recherche du GéPS, 2(6), $1-37$.

Giddens, A. (2009). A constituição da sociedade (3a ed.). São Paulo: Martins Fontes.

Grimmelikhuijsen, S. G., Meijer, A. J. (2015). Does Twitter increase perceived police legitimacy? Public Administration Review, 75(4), 598-607.

International Association of Chiefs of Police. (2011). 2011 IACP Social Media Survey. Recuperado de http://www. iacpsocialmedia.org/wp-content/uploads/2017/01/2011SurveyResults.pdf

Kaplan, A. M., Haenlein, M. (2010). Users of the world, unite! The challenges and opportunities of Social Media. Business horizons, 53(1), 59-68.

Langley, A. (1999). Strategies for theorizing from process data. Academy of Management review, 24(4), 691-710.

Langley, A., Abdallah, C. (2011). Templates and turns in qualitative studies of strategy and management. In Building methodological bridges, (pp. 201-235). Emerald Group Publishing Limited.

Latour, B. (1999). On Recalling ANT. In J. Law and J. Hassard (Eds.) Actor Network Theory and After, (pp. 15-26). Oxford: Blackwell/The Sociological Review.

Lieberman, J. D., Koetzle, D., Sakiyama, M. (2013). Police departments' use of Facebook: Patterns and policy issues. Police quarterly, 16(4), 438-462.

Manning, P. K. (2005). Os estudos sobre a polícia nos países anglo-americanos. Caderno CRH, 18(45), 431-446.

Manning, P. K. (2003). As tecnologias de informação e a polícia. TONRY, Michael.

Meijer, A. J. (2014). From Hero-Innovators to Distributed Heroism: An in-depth analysis of the role of individuals in public sector innovation. Public Management Review, 16(2), 199-216.

Meijer, A., Thaens, M. (2013). Social media strategies: Understanding the differences between North American police departments. Government Information Quarterly, 30(4), 343-350.

Meijer, A. J., Torenvlied, R. (2016). Social media and the new organization of government communications: An empirical analysis of Twitter usage by the Dutch police. The American Review of Public Administration, 46(2), 143-161.

Muniz, J., Proença, D., Jr. (2014). Mandato policial. Crime, polícia e justiça no Brasil, (pp. 491-502). São Paulo: Contexto.

O'Connor, C. D. (2015). The police on Twitter: image management, community building, and implications for policing in Canada. Policing and society, 27(8), 899-912. doi: 10.1080/10439463.2015.1120731

Oliveira, A., Jr. (2007). Cultura de polícia: cultura e afitudes ocupacionais entre policiais militares em Belo Horizonte. (Tese de Doutorado). Universidade Federal de Minas Gerais, Belo Horizonte, Brasil.

Orlikowski, W. (2015). Practice in research: Phenomenon, perspective and philosophy. In D. Golsorkhi, L. Rouleau, D. Seidl, \& E. Vaara (Eds.), Cambridge Handbook of Strategy as Practice, (pp. 33-43). Cambridge: Cambridge University Press. doi:10.1017/CBO9781139681032.002 
Mirian Assumpção e Lima, et al. O Emprego das Mídias Sociais no Policiamento: Um Estudo sob a Lent...

Orlikowski, W. J. (2000). Using Technology and Constituting Structures: A Practice Lens for Studying Technology in Organizations. Organization Science, 11(4), 404-428.

Orlikowski, W. J. (1992). The duality of technology: Rethinking the concept of technology in organizations. Organization science, 3(3), 398-427.

Ouirdi, M. E., El Ouirdi, A., Segers, J., Henderickx, E. (2014). Social media conceptualization and taxonomy: A Lasswellian framework. Journal of Creative Communications, 9(2), 107-126.

Porto, M. S. G. (2009). Mídia, segurança pública e representações sociais. Tempo social, 21(2), 211-233.

Pozzebon, M., Pinsonneault, A. (2000). The structuration theory in IS: usage patterns and methodological issues. École des hautes études commerciales, Groupe de recherche en systèmes d'information.

Stake, R.E. (2005). Qualitative Case Studies. In Denzin, N.K., \& Lincoln, Y.S. The Sage Handbook of qualitative research (pp. 443-466). (3rd ed.). California: Sage Publications.

Strauss, A. L., Corbin, J. (2008). Pesquisa qualitativa: técnicas e procedimentos para o desenvolvimento de teoria fundamentada. Porro Alegre: Artmed.

Trottier, D. (2015). Coming to terms with social media monitoring: Uptake and early assessment. Crime, Media, Culture, 11(3), 317-333.

Trottier, D. (2012). Policing social media. Canadian Review of Sociology / Revue Canadienne de Sociologie, 49(4), 411-425. 